\title{
A relação entre parturição e trabalho feminino no Brasil
}

\author{
Laetícia Rodrigues de Souza* \\ Eduardo Luiz Gonçalves Rios-Neto** \\ Bernardo Lanza Queiroz***
}

\begin{abstract}
O objetivo desse artigo é analisar o efeito dos filhos sobre a participação das mulheres na População Economicamente Ativa (PEA), observando a evolução temporal desse efeito desde os anos de 1990. Além disso, com base no fato de que cada filho possa apresentar um efeito diferenciado sobre a decisão de trabalho das mães, estimou-se, separadamente, o efeito do primeiro, do segundo e do terceiro (ou mais) filhos sobre a participação feminina na PEA. De maneira geral, os resultados sugerem que, independentemente da ordem de nascimento, os filhos diminuem a probabilidade de participação das mulheres no mercado de trabalho. Ademais, entre as décadas de 1990 e 2000, o efeito negativo do primeiro e segundo filhos sobre a participação feminina no mercado de trabalho perdeu magnitude, ao passo que o efeito do terceiro filho ganhou importância.
\end{abstract}

Palavras-chave: Fecundidade. Oferta de trabalho. Mulheres. Brasil.

\section{Introdução}

A relação entre filhos e o engajamento dos pais, especialmente das mulheres, no mercado de trabalho vem sendo discutida tanto em países desenvolvidos (GOLDIN, 1997; ANGRIST; EVANS, 1998; MARON; MEULDERS, 2008) quanto naqueles em desenvolvimento (SOUTO-MAIOR, 1990; RIOS-NETO, 1996; CRUCES; GALIANI, 2003). Em anos recentes, o interesse nessa relação foi especialmente motivado pelas rápidas e profundas transformações ocorridas na função econômica, social e familiar das mulheres nas últimas décadas (BECKER, 1981; SCORZAFAVE, 2001). No Brasil, assim como em diversos outros países, a oferta de trabalho feminina aumentou ao mesmo tempo em que a taxa de fecundidade declinou rapidamente (ENGELHART, 2004). Essa concomitância intensificou o debate em torno dos possíveis efeitos causais entre essas duas variáveis (RIOS-NETO, 1996; GOLDIN; KATZ, 2002).

O objetivo desse artigo é estimar o efeito da maternidade sobre a participação feminina na População Economicamente Ativa (PEA), observando sua evolução tem-

\footnotetext{
* Doutora em Demografia pela Universidade Federal de Minas Gerais, Pós-doc. do Center for Demography and Ecology, University of Wisconsin, Madison.

** Doutor em Demografia pela Universidade da Califórnia, Berkeley. Professor titular do Departamento de Demografia da Universidade Federal de Minas Gerais e pesquisador do Cedeplar/UFMG.

${ }_{* \star *}$ Doutor em Demografia pela Universidade da Califórnia, Berkeley. Professor adjunto do Departamento de Demografia da Universidade Federal de Minas Gerais e pesquisador do Cedeplar/UFMG.
} 
poral desde os anos de 1990. Além disso, com base no fato de que cada filho possa apresentar um efeito diferenciado sobre a decisão de trabalho das mães, já que há evidências, por exemplo, de que o primeiro filho é aquele com o efeito mais forte sobre a entrada ou permanência da mãe no mercado de trabalho (LÉRIDA, 2006), estimamos, separadamente, o efeito do primeiro, do segundo e do terceiro (ou mais) filhos sobre a participação feminina no mercado de trabalho. ${ }^{1}$

O maior conhecimento do efeito da maternidade - e da decisão de ter filhos sobre a participação feminina no mercado de trabalho tem grande relevância, já que, comparativamente aos homens, pode ser que os filhos limitem de alguma forma o crescimento profissional das mulheres, no que se refere tanto aos diferenciais salariais quanto aos tipos de ocupação (PAZELLO, 2006).

Como sugerem Maron e Meulders (2008), a maternidade pode levar as mulheres a desistirem de trabalhar (temporária ou definitivamente), encorajá-las a reduzir seu tempo de trabalho ou até mesmo fazer com que mudem de profissão ou de segmento do mercado, além de poder retardar sua promoção a melhores cargos e aumentos salariais. Adicionalmente, destaca-se o fato de que o estudo da relação filhos-trabalho faz parte de uma análise mais ampla da dinâmica do comportamento familiar. Conhecer melhor essa dinâmica contribui significativamente para a formulação de políticas públicas que considerem de forma distinta os membros familiares e seus papéis dentro da família, além de levantar importantes questões para as projeções de oferta de mão de obra feminina (SEDLACEK; SANTOS, 1991; RIOS-NETO; WAJNMAN, 1994; JANNUZZI, 2000).

Devido ao fato de que trabalhar e ter filhos constituem decisões, muitas vezes, tomadas simultaneamente, estimar o efeito de filhos sobre a participação das mães não é tarefa trivial, já que os métodos convencionais não permitem estimar corretamente uma relação de causalidade, mas apenas a associação entre elas (ANGRIST; EVANS, 1998).

Assim, mensuramos o efeito da fecundidade sobre a participação feminina na PEA por meio do uso de experimentos naturais ou quase-naturais. Essa estratégia consiste em encontrar uma variável - em geral, relacionada a um evento natural, biológico - que afete a fecundidade (e tenha relação com a decisão de ter filhos) e só influencie a oferta de trabalho feminina por meio da fecundidade. Dessa forma, eliminamos a endogeneidade da relação filhos-trabalho feminino, que, em modelos tradicionais, impediria estimar o efeito de interesse.

Em se tratando do efeito de filhos sobre a participação feminina no mercado de trabalho, a ocorrência de natimortos, o nascimento de gêmeos e a preferência dos pais por filhos de ambos os sexos são eventos que vêm sendo empregados na literatura. Destaca-se, entretanto, que, segundo o nosso conhecimento, ou essas variáveis foram utilizadas de maneira isolada nos estudos anteriores, ou foram feitas comparações nos efeitos de filhos estimados com base em duas delas, desconsiderando o diferencial do efeito de filhos de acordo com sua ordem de nascimento (BRONARS; GROGGER, 1994; ANGRIST; EVANS, 1998; CRUCES; GALIANI, 2003; PAZELLO; FERNANDES, 2004; PAZELLO, 2006).

$O$ presente artigo analisa o efeito dos filhos sobre a presença feminina na PEA, considerando os três eventos, de acordo com a parturição da mulher, o que permite estimar o efeito do primeiro, segundo e terceiro (ou mais) filhos sobre a participação feminina no mercado de trabalho. Na litera-

\footnotetext{
1 Soares (2002) analisa se o sexo e a idade dos filhos exercem influência sobre a participação de mães e pais no mercado de trabalho. Em relação aos filhos mais velhos (maiores de 12 anos), o autor verifica a existência de um viés de gênero na participação materna no mercado de trabalho: enquanto os filhos do sexo masculino com mais de 12 anos de idade reduzem a probabilidade de trabalho da mãe, as filhas dessa idade aumentam. Nosso objetivo, entretanto, é estimar o efeito da presença de filhos, independentemente do sexo ou da idade destes, sobre a participação feminina no mercado de trabalho.
} 
tura que aborda o efeito de filhos sobre a decisão de oferta de trabalho das mulheres, essa perspectiva de ordem de nascimento revela-se como importante contribuição.

Inicialmente, estimamos o efeito do primeiro filho sobre a participação das mulheres na PEA, utilizando a ocorrência de natimortos como proxy exógena para a fecundidade, de modo que comparamos as mulheres que não tinham filhos, mas já haviam tido, pelo menos, um natimorto, com aquelas que tinham apenas um filho (e nunca tiveram um natimorto). A ideia implícita nessa estimativa é comparar uma mulher que tenha um ou mais filhos com outra que tentou ter filhos, mas não conseguiu. Nesse sentido, assume-se que essas mulheres teriam preferências ex-ante similares, já que o desejo de ter filhos foi comum para ambas.

Em segundo lugar, para estimar o efeito do segundo filho sobre a participação das mães na PEA, utilizamos o nascimento de gêmeos como proxy para um aumento exógeno na fecundidade, por ser considerado um evento não planejado sobre as decisões das mães em relação a ter mais filhos, casar, estudar e trabalhar (BRONARS; GROGGER, 1994). Nesse caso, comparamos as mães que tiveram gêmeos na primeira gravidez com aquelas que tinham apenas um filho.

A evidência empírica aponta para efeitos negativos da maternidade sobre a participação das mulheres no mercado de trabalho, estimados tanto com base no nascimento de gêmeos (BRONNARS; GROGGER, 1994; JACOBSEN; PEARCE III; ROSENBLOOM, 1999; PAZELLO, 2006) quanto na ocorrência de natimortos (PAZELLO; FERNANDES, 2004).

Por último, estimamos o efeito de um terceiro ou mais filhos sobre a participação feminina no mercado de trabalho, utilizando uma variável instrumental baseada na preferência dos pais por filhos de ambos os sexos. Isto porque há evidências de que os pais com os dois primeiros filhos do mesmo sexo apresentam probabilidade maior de terem um terceiro ou mais filhos em relação àqueles cujos dois primeiros filhos são uma menina e um menino (ANGRIST; EVANS, 1998; CRUCES; GALIANI, 2003; CAMPÊLO; SILVA, 2005). Nessa estimativa do efeito de um filho adicional a partir do terceiro sobre a participação feminina na PEA, comparamos as mulheres que tinham mais de dois filhos, sendo os dois primeiros do mesmo sexo, com aquelas que tinham apenas dois filhos, sendo um menino e uma menina. A evidência empírica mostra uma redução da oferta de trabalho feminino devido ao nascimento do terceiro filho tanto em países em desenvolvimento (CRUCES; GALIANI, 2003; CAMPELO; SILVA, 2005) como naqueles desenvolvidos (ANGRIST; EVANS, 1998).

Os resultados do nosso estudo mostram que ter filhos diminui a probabilidade de inserção feminina no mercado de trabalho, independentemente da ordem de nascimento destes e do estado conjugal das mulheres. No que se refere à evolução no tempo, o efeito do primeiro e segundo filhos apresentou tendência de queda entre as décadas de 1990 e 2000, ao passo que um filho adicional a partir do terceiro tende a afetar mais negativamente a participação feminina na PEA nos anos de 2000 do que na década anterior. Com relação à magnitude dos efeitos, o segundo filho apresentou o efeito negativo mais forte sobre a participação das mulheres no mercado de trabalho, o que não seria esperado (pois se espera que o primeiro filho tenha o efeito mais negativo) não fosse o evento utilizado como proxy para a fecundidade. Como mensuramos o efeito do segundo filho por meio do nascimento recente de gêmeos, o efeito estimado deve ser considerado um limite superior para o efeito do segundo filho, uma vez que no curto prazo há uma deseconomia de escala em ter dois filhos ao mesmo tempo (PAZELLO, 2006).

A literatura relacionada ao efeito de filhos sobre a decisão de trabalho dos pais é ainda incipiente. Primeiramente porque, em geral, os estudos utilizam apenas um ponto no tempo, sem fornecer uma noção de como esse efeito tem mudado ao longo dos anos. O presente trabalho contém informações que permitem investigar essa evolução ao longo das duas últimas décadas; um período que compreende mudanças significativas nas mais variadas dimensões da vida social brasileira. Além disso, a necessidade da utilização de proxies/instrumentos para 
a mensuração do efeito de filhos sobre a participação das mulheres na PEA faz com que as estimativas obtidas não possam ser generalizadas para o conjunto da população e, nesse sentido, esse artigo constitui importante fonte de validação externa para o uso de experimentos naturais na estimação do efeito de filhos sobre a participação feminina no mercado de trabalho.

\section{Dados}

Utilizamos a série das PNADs (Pesquisa Nacional por Amostra de Domicílios) realizadas entre 1992 e 2007, ${ }^{2}$ empilhadas a cada decênio, de forma a gerar dois bancos de dados (um com as PNADs de 1992 a 1999 e outro com as de 2001 a 2007) para cada estimação do efeito de filhos (primeiro, segundo e terceiro ou mais filhos) sobre a participação laboral feminina. A justificativa para o empiIhamento está no fato de que estamos lidando com eventos raros (natimortos e gêmeos). Já no caso de filhos do mesmo sexo, evento não-raro, o empilhamento permite maior comparabilidade entre os modelos testados.

Idealmente, para estimarmos o efeito do primeiro filho sobre a participação das mulheres no mercado de trabalho, por exemplo, precisaríamos observar a participação laboral de uma mesma mulher em um mesmo momento, em duas situações: "sem filhos" e "mãe de um filho". Como isso é impossível, a utilização de experimentos naturais permite simular situação semelhante, de forma que o fato de uma mulher experimentar ou não um evento (fonte de variação exógena na fecundidade) a classifica como "tratamento" ou "controle", respectivamente, o que define a construção de um contra-factual.

Assim, na estimação do efeito do primeiro filho sobre a decisão de trabalho feminina, comparamos dois grupos de mulheres: aquelas que não tinham filhos, mas já haviam tido, pelo menos, um natimorto (tratamento); e as que tinham apenas um filho e nunca tiveram um natimorto (controle). Ao estimarmos o efeito do segundo filho, aquelas que fazem parte do grupo tratamento são as mães que tiveram gêmeos na primeira gravidez e as controles compreendem aquelas que tinham apenas um filho. Já na estimação do efeito de um filho adicional a partir do terceiro, o grupo tratamento é formado pelas mães com mais de dois filhos e o de controle, por aquelas com apenas dois.

Como cada evento (natimortos, gêmeos e preferência por filhos de ambos os sexos) tem sua singularidade em termos do seu uso como proxies/instrumento para a fecundidade, em cada estimação, as amostras foram definidas separadamente. A Tabela 1 contém os tamanhos amostrais e os filtros necessários à construção das amostras dos grupos tratamento e controle usadas nas três estimações do efeito de filhos sobre a participação feminina na PEA contempladas nesse artigo.

$\mathrm{Na}$ análise descritiva dos dados aqui realizada, são discutidas apenas as características médias das amostras que incluem, para cada estimação do efeito de filhos sobre a oferta de trabalho feminina, todas as mulheres de 15 a 49 anos de idade, somente na década de 1990.

As Tabelas 2, 3 e 4 apresentam as características sociodemográficas, geográficas, domiciliares e ocupacionais que descrevem os grupos de tratamento e controle utilizados na estimação do efeito do primeiro, segundo e terceiro (ou mais) filhos sobre a participação feminina na PEA, respectivamente.

$\mathrm{Na}$ Tabela 2, comparamos as mulheres sem filhos que já tiveram algum natimorto (tratamento) com aquelas que tinham um filho e nunca tiveram um natimorto (controle), ambos os grupos de mulheres utilizados na estimação do efeito do primeiro filho sobre a participação feminina no mercado laboral. O que mais chama a atenção é o fato de que a ocorrência de natimortos parece estar associada a condições de pobreza das mulheres, sugerindo que esse evento não seja aleatório.

\footnotetext{
2 Diversas PNADs anteriores à de 1992 não têm informação sobre natimortos, razão pela qual optamos por trabalhar apenas com as PNADs a partir de 1992, sendo que a PNAD de 1990 foi excluída por ser a única da década a captar o status de trabalho segundo a antiga metodologia.
} 


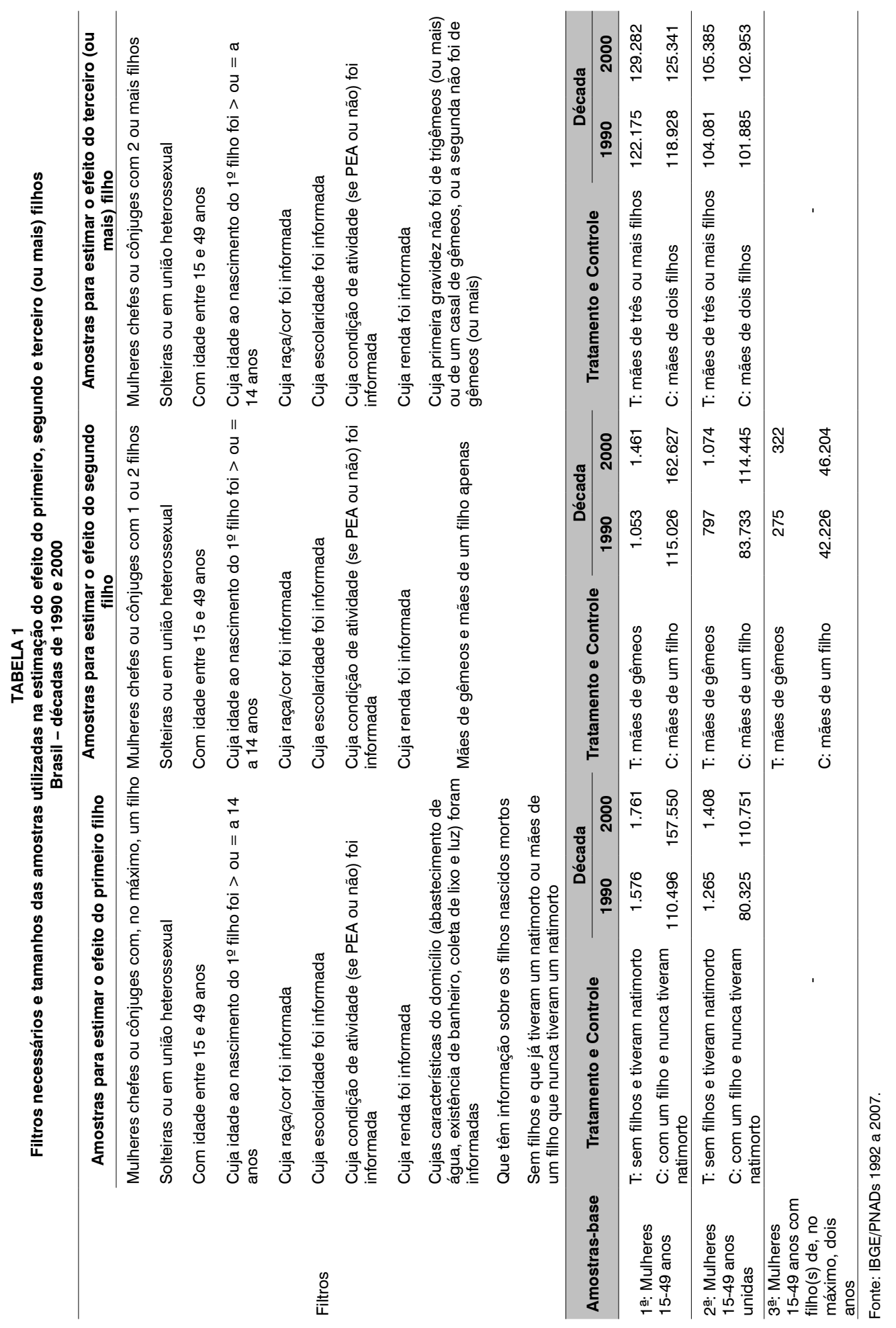


Observou-se, também, que as mulheres-controle são mais escolarizadas $(6,83$ anos médios de estudo, contra 4,59 das mulheres do grupo tratamento), auferem rendas superiores (cerca de $\mathrm{R} \$ 105,36$ a mais) e apresentam maior proporção de brancas $(61,19 \%)$ em relação às mulheres- -tratamento (46,88\%). Além disso, há uma menor proporção de mulheres do grupo tratamento residindo em regiões de maior desenvolvimento econômico e, em contrapartida, uma maior representatividade dessas nas regiões ditas menos desenvolvidas. Em se tratando das características ocupa-

TABELA 2

Características sociodemográficas, geográficas, domiciliares e ocupacionais selecionadas para mulheres de 15 a 49 anos, por ocorrência de natimortos Brasil - décadas de 1990 e 2000

\begin{tabular}{|c|c|c|c|c|c|c|c|c|}
\hline \multirow{2}{*}{ Características } & \multicolumn{4}{|c|}{ Década de 1990} & \multicolumn{4}{|c|}{ Década de 2000} \\
\hline & $T(1)$ & C (2) & \multicolumn{2}{|l|}{ Dif. (3) } & $T(1)$ & C (2) & \multicolumn{2}{|c|}{ Dif. (3) } \\
\hline \multicolumn{9}{|l|}{ Sociodemográficas } \\
\hline Brancas (\%) & 46,88 & 61,19 & $-14,31$ & $\star \star \star *$ & 44,94 & 55,58 & $-10,64$ & $\star * *$ \\
\hline Unidas (\%) & 81,01 & 74,07 & 6,94 & $\star * *$ & 80,42 & 71,40 & 9,02 & $\star * *$ \\
\hline Chefes (\%) & 21,72 & 27,64 & $-5,92$ & 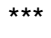 & 27,15 & 33,28 & $-6,13$ & $\star \star *$ \\
\hline \multirow{2}{*}{ Idade média } & 35,69 & 30,72 & 4,97 & 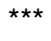 & 37,99 & 32,23 & 5,76 & $\star \star \star$ \\
\hline & $(10,08)$ & $(9,10)$ & & & $(9,50)$ & $(9,24)$ & & \\
\hline \multirow{2}{*}{ Anos médios de estudo } & 4,59 & 6,83 & $-2,23$ & 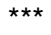 & 5,73 & 8,12 & $-2,39$ & $\star \star \star *$ \\
\hline & $(3,96)$ & $(4,01)$ & & & $(4,20)$ & $(3,93)$ & & \\
\hline \multicolumn{9}{|l|}{ Geográficas (\%) } \\
\hline \multicolumn{9}{|l|}{ Região de residência } \\
\hline Sul & 13,81 & 19,03 & $-5,22$ & $\star \star \star *$ & 13,86 & 17,22 & $-3,36$ & $\star \star *$ \\
\hline Sudeste & 41,35 & 46,67 & $-5,32$ & $\star \star * \star$ & 35,05 & 44,76 & $-9,71$ & $\star \star *$ \\
\hline Norte & 5,76 & 4,18 & 1,58 & $\star \star \star *$ & 8,68 & 5,83 & 2,85 & $\star \star \star *$ \\
\hline Nordeste & 30,32 & 22,76 & 7,56 & 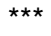 & 31,05 & 24,78 & 6,27 & $* * *$ \\
\hline Centro-Oeste & 8,77 & 7,36 & 1,41 & 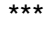 & 11,37 & 7,39 & 3,98 & $\star \star \star *$ \\
\hline \multicolumn{9}{|l|}{ Situação de residência } \\
\hline Urbana & 79,14 & 85,09 & $-5,95$ & $\star \star \star *$ & 84,40 & 88,37 & $-3,97$ & $\star \star \star *$ \\
\hline \multicolumn{9}{|l|}{ Área de residência } \\
\hline Metropolitana & 28,84 & 34,47 & $-5,63$ & $\star \star \star *$ & 24,78 & 33,47 & $-8,69$ & $\star \star \star *$ \\
\hline \multicolumn{9}{|l|}{$\begin{array}{l}\text { Domiciliares (no domicílio em que } \\
\text { reside, há...) (\%) }\end{array}$} \\
\hline Ao menos um banheiro & 83,57 & 92,82 & $-9,25$ & $\star \star \star *$ & 91,52 & 96,07 & $-4,55$ & $\star \star *$ \\
\hline $\begin{array}{l}\text { Rede geral de abastecimento de } \\
\text { água }\end{array}$ & 64,99 & 77,40 & $-12,41$ & *** & 75,14 & $83, .23$ & $-8,09$ & $\star \star * *$ \\
\hline Serviço de coleta de lixo & 59,09 & 72,04 & $-12,95$ & $* \star *$ & 73,83 & 81,38 & $-7,55$ & $\star \star *$ \\
\hline Iluminação elétrica & 89,86 & 95,53 & $-5,67$ & $\star \star \star *$ & 95,76 & 98,46 & $-2,70$ & $* * *$ \\
\hline \multicolumn{9}{|l|}{ Ocupacionais } \\
\hline Ativas (\%) & 64,62 & 59,29 & 5,33 & $\star \star \star *$ & 67,83 & 67,40 & 0,43 & $* * *$ \\
\hline \multirow{2}{*}{$\begin{array}{l}\text { Renda média familiar (em reais de } \\
\text { 2001), (4) }\end{array}$} & 296,13 & 431,33 & $-135,20$ & $* * *$ & 1078,19 & 1524,04 & $-445,85$ & $* * *$ \\
\hline & $(610,22)$ & $(885,26)$ & \multicolumn{6}{|c|}{$(1454,77)(2526,80)$} \\
\hline \multirow{2}{*}{$\begin{array}{l}\text { Renda média do não trabalho (em } \\
\text { reais de 2001) (4) (5) }\end{array}$} & 212,41 & 317,77 & $-105,36$ & $* \star *$ & 787,11 & 1073,01 & $-285,89$ & $* * *$ \\
\hline & $(507,61)$ & $(719,38)$ & \multicolumn{6}{|c|}{$(1241,46)(1961,38)$} \\
\hline $\begin{array}{l}\text { Jornada de trabalho de, ao } \\
\text { menos, } 40 \text { horas semanais (\%) (4) }\end{array}$ & 34,77 & 34,70 & 0,07 & & 39,21 & 41,18 & $-1,97$ & $* * *$ \\
\hline Observações & 1.576 & 110.496 & & - & 1.761 & 157.550 & & \\
\hline
\end{tabular}

Fonte: IBGE/PNADs 1992 a 2007.

(1) Tratamento (já teve natimorto).

(2) Controle (nunca teve natimorto).

(3) Teste de diferença: T - C; Hipótese nula: T = C.

(4) Foram consideradas renda zero e jornada de zero horas para quem não trabalhava, por isso a amostra de mulheres é sempre a mesma.

(5) Renda do não trabalho = renda familiar subtraída da renda de todos os trabalhos da própria mulher.

$\star \star \star$ Significativo a $1 \%$.

Nota: Os dados entre parênteses correspondem aos erros-padrão. 
cionais, existe maior proporção de mulheres ativas no grupo tratamento. Isso pode estar sinalizando um possível efeito negativo do primeiro filho sobre a condição de atividade das mulheres. Mas, como essa análise não controla por nenhuma outra característica (apenas compara a proporção de mulheres nos grupos tratamento e controle que são ativas), pode ser que esse diferencial entre mulheres tratamento e controle reflita fatores que vão além da presença de filhos.

A Tabela 3 compara as características sociodemográficas, geográficas e ocupacionais das mães de gêmeos (tratamento) com

TABELA 3

Características sociodemográficas, geográficas e ocupacionais selecionadas para mulheres de 15 a 49 anos, por ocorrência de nascimento de gêmeos Brasil - décadas de 1990 e 2000

\begin{tabular}{|c|c|c|c|c|c|c|c|c|}
\hline \multirow{2}{*}{ Características } & \multicolumn{4}{|c|}{ Década de 1990} & \multicolumn{4}{|c|}{ Década de 2000} \\
\hline & $T(1)$ & C (2) & \multicolumn{2}{|c|}{ Dif. (3) } & $T(1)$ & C (2) & \multicolumn{2}{|c|}{ Dif. (3) } \\
\hline Brancas (\%) & 66,12 & 60,81 & 5,31 & $\star \star \star *$ & 59,84 & 55,31 & 4,53 & $\star \star \star$ \\
\hline Unidas (\%) & 77,33 & 74,16 & 3,17 & $\star \star * *$ & 74,43 & 71,50 & 2,93 & $\star * *$ \\
\hline Chefes (\%) & 24,69 & 27,58 & $-2,89$ & $\star \star \star *$ & 30,36 & 33,23 & $-2,87$ & 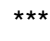 \\
\hline Idade média corrente & $\begin{array}{l}33,98 \\
(8,54)\end{array}$ & $\begin{array}{l}30,91 \\
(9,15)\end{array}$ & 3,07 & *** & $\begin{array}{l}34,47 \\
(8,59)\end{array}$ & $\begin{array}{l}32,37 \\
(9,25)\end{array}$ & 2,10 & $\star \star \star *$ \\
\hline Idade média ao ter o(s) filho(s) & $\begin{array}{l}26,08 \\
(5,57)\end{array}$ & $\begin{array}{l}24,17 \\
(5,66)\end{array}$ & 1,90 & $\star * *$ & $\begin{array}{l}25,53 \\
(5,57)\end{array}$ & $\begin{array}{l}24,22 \\
(5,69)\end{array}$ & 1,31 & $\star \star \star *$ \\
\hline Anos médios de estudo & $\begin{array}{r}7,18 \\
(4,17) \\
\end{array}$ & $\begin{array}{r}6,76 \\
(4,03) \\
\end{array}$ & 0,42 & $\star \star \star *$ & $\begin{array}{r}8,22 \\
(4,20) \\
\end{array}$ & $\begin{array}{r}8,06 \\
(3,95) \\
\end{array}$ & 0,16 & $\star \star \star *$ \\
\hline \multicolumn{9}{|l|}{ Geográficas (\%) } \\
\hline \multicolumn{9}{|l|}{ Região de residência } \\
\hline Sul & 19,36 & 18,92 & 0,44 & $\star \star \star *$ & 19,67 & 17,13 & 2,54 & $\star \star \star *$ \\
\hline Sudeste & 52,55 & 46,45 & 6,10 & $\star \star \star *$ & 45,65 & 44,67 & 0,98 & $\star * *$ \\
\hline Norte & 3,88 & 4,24 & $-0,36$ & $\star * \star$ & 4,63 & 5,86 & $-1,23$ & $\star * *$ \\
\hline Nordeste & 16,97 & 22,95 & $-5,98$ & $\star * *$ & 22,25 & 24,90 & $-2,65$ & $\star * *$ \\
\hline Centro-Oeste & 7,23 & 7,45 & $-0,22$ & $\star \star \star *$ & 7,80 & 7,43 & 0,37 & $\star \star *$ \\
\hline \multicolumn{9}{|l|}{ Situação de residência } \\
\hline Urbana & 87,93 & 84,95 & 2,98 & $\star \star \star *$ & 89,75 & 88,31 & 1,44 & $* * *$ \\
\hline \multicolumn{9}{|l|}{ Área de residência } \\
\hline Metropolitana & 34,67 & 34,30 & 0,37 & $\star * *$ & 34,74 & 33,41 & 1,33 & $\star * *$ \\
\hline \multicolumn{9}{|l|}{ Ocupacionais } \\
\hline Ativas (\%) & 57,58 & 59,34 & $-1,76$ & $\star \star \star *$ & 65,34 & 67,36 & $-2,02$ & $\star \star \star$ \\
\hline $\begin{array}{l}\text { Renda média familiar (em reais de } \\
\text { 2001) (4) }\end{array}$ & $\begin{array}{r}542,31 \\
(965,58)\end{array}$ & $\begin{array}{r}428,01 \\
(877,51)\end{array}$ & 114,30 & $* * *$ & $\begin{array}{r}1967,39 \\
(2979,98)\end{array}$ & $\begin{array}{r}1516,26 \\
(2509,29)\end{array}$ & 451,13 & $* * *$ \\
\hline $\begin{array}{l}\text { Renda média do não trabalho (em } \\
\text { reais de 2001) (4) (5) }\end{array}$ & $\begin{array}{r}401,90 \\
(758,56)\end{array}$ & $\begin{array}{r}315,51 \\
(713,25)\end{array}$ & 86,39 & $\star \star *$ & $\begin{array}{r}1424,55 \\
(2239,95)\end{array}$ & $\begin{array}{r}1068,66 \\
(1949,35)\end{array}$ & 355,90 & $* * *$ \\
\hline $\begin{array}{l}\text { Jornada de trabalho de, ao } \\
\text { menos, } 40 \text { horas semanais (\%) (4) }\end{array}$ & 34,31 & 34,59 & $-0,28$ & $\star \star \star$ & 38,98 & 41,08 & $-2,10$ & $\star \star \star$ \\
\hline Observações & 1.053 & 115.026 & & - & 1.461 & 162.627 & & - \\
\hline
\end{tabular}

Fonte: IBGE/PNADs 1992 a 2007.

(1) $T=$ Tratamento (tem gêmeos)

(2) $\mathrm{C}=$ Controle (tem um filho).

(3) Teste de diferença: T - C; Hipótese nula: T = C.

(4) Foram consideradas renda zero e jornada de zero horas para quem não trabalhava, por isso, a amostra de mulheres é sempre a mesma.

(5) Renda do não trabalho = renda familiar subtraída da renda de todos os trabalhos da própria mulher.

$\star \star \star$ Significativo a $1 \%$.

Nota: Os dados entre parênteses correspondem aos erros-padrão. 
aquelas que possuem um filho (controle), grupos que compõem a amostra utilizada na estimação do efeito do segundo filho sobre a participação das mães na PEA.

No caso do nascimento de gêmeos, verifica-se que esse fenômeno está associado a melhores condições de vida, pois, além de as mulheres-tratamento serem mais escolarizadas (7,18 anos médios de estudo, contra 6,76 do grupo controle) e apresentarem maior renda média mensal familiar (superior em $\mathrm{R} \$ 86,39$ à das mães de apenas um filho), há maior percentual de mães de gêmeos em regiões mais desenvolvidas do país (como no Sudeste e em áreas urbanas) e uma menor representatividade dessas nas regiões ditas menos desenvolvidas (como no Nordeste) em relação às mães de não-gêmeos. Tais características, por estarem associadas a melhores condições de vida e aos recursos médicos mais avançados, sugerem uma associação positiva entre renda e probabilidade de ocorrência de gêmeos (COLLETTO; SEGRE; BEIGUELMAN, 2001).

Além disso, as mulheres-tratamento são, em média, mais velhas e tiveram seus filhos gêmeos também mais tarde quando comparadas às do grupo controle (considerando-se todas as mães de 15 a 49 anos, a idade média ao ter o filho das mulheres do grupo tratamento é de 26,08 anos, enquanto para as de controle corresponde a 24,17 anos). De fato, há evidências empíricas de que as mães de gêmeos são mais escolarizadas e mais velhas do que aquelas que não tiveram gêmeos, porque mulheres consideradas "mais produtivas" tendem a atrasar a maternidade. Além disso, quanto maior a idade em que a mulher engravida, maior é a probabilidade de que ela tenha gêmeos, seja porque a ovulação tende a se tornar mais irregular com o aumento da idade, seja devido aos tratamentos hormonais a que as mulheres mais velhas se submetem para engravidar (PAZELLO, 2006).

Por fim, temos o exercício realizado com base na informação de filho adicional a partir do terceiro nascimento. Nesse caso, a fonte de variação exógena na fecundidade é um instrumento e não uma proxy para a fecundidade (como no caso dos natimortos e gêmeos). Isso significa que, enquanto os demais eventos produzem necessariamente uma variação exógena na fecundidade (sendo que os natimortos representam a "perda inesperada" de um filho e o nascimento de gêmeos significa o "ganho inesperado" de um filho), o fato de haver evidências de que os pais, em geral, preferem ter filhos de ambos os sexos, embora aumente a probabilidade de nascimento de um terceiro filho quando os dois primeiros são do mesmo sexo, não garante que isso ocorra. Devido a essa particularidade, a análise descritiva do banco de dados utilizado na estimação do efeito do terceiro (ou mais) filho sobre a participação feminina no mercado de trabaIho é diferenciada das demais. Nesse caso, torna-se crucial verificar se as mulheres que tiveram os dois primeiros filhos do mesmo sexo apresentam maior probabilidade de terem um terceiro filho em relação àquelas que tiveram uma menina e um menino. $\mathrm{Na}$ Tabela 4 observamos, para as mães de duas ou mais crianças, a relação entre a porcentagem destas que tiveram um terceiro filho e 0 sexo dos seus dois primeiros filhos.

A preferência dos pais por filhos de ambos os sexos é um fenômeno que tem sido tema de vários estudos. Angrist e Evans (1998) mostraram que a probabilidade de uma família ter um filho adicional depende, significativamente, do sexo dos filhos já tidos. Segundo os autores, apenas 34,4\% de todas as mulheres norte-americanas que tinham, em 1990, um menino e uma menina tiveram outro filho, enquanto para aquelas que tinham dois meninos ou duas meninas, no mesmo ano, esse percentual chega a $40,7 \%$. A Tabela 4 reporta estimativas similares a essas para o Brasil, nas décadas de 1990 e 2000.

Os resultados indicam uma preferência estatisticamente significativa dos pais por filhos de ambos os sexos, também no Brasil. Por exemplo, enquanto $47,04 \%$ das mães de 15 a 49 anos com um casal de filhos tinham um terceiro filho, em 1990, para aquelas com dois meninos ou duas meninas esse percentual é de $51,16 \%$.

$\mathrm{Na}$ Tabela 5, que apresenta as estatísticas descritivas das mulheres de 15 a 49 anos com, ao menos, dois filhos (amostra-base da estimação do efeito do terceiro filho 
TABELA 4

Proporção de mães de 15 a 49 anos de idade com dois ou mais filhos, segundo o sexo das duas primeiras crianças

Brasil - décadas de 1990 e 2000

\begin{tabular}{|c|c|c|c|c|}
\hline \multirow[b]{2}{*}{ Sexo dos dois primeiros filhos } & \multicolumn{2}{|c|}{ Década de 1990} & \multicolumn{2}{|c|}{ Década de 2000} \\
\hline & $\%$ na amostra & $\begin{array}{l}\% \text { que teve } \\
\text { outra criança }\end{array}$ & $\%$ na amostra & $\begin{array}{c}\% \text { que teve } \\
\text { outra criança }\end{array}$ \\
\hline \multirow{2}{*}{ (A) Um menino e uma menina } & 49,42 & 47,04 & 49,19 & 38,50 \\
\hline & $(0,50)$ & $(0,50)$ & $(49,99)$ & $(48,66)$ \\
\hline \multirow{2}{*}{ (B) Ambos do mesmo sexo } & 50,58 & 51,16 & 50,81 & 42,12 \\
\hline & $(0,50)$ & $(0,50)$ & $(49,99)$ & $(49,37)$ \\
\hline Diferença $(B)$ - $(A)$ & & 4,12 & & 3,62 \\
\hline Valor $p$ & & 0,00 & & 0,00 \\
\hline Observações & \multicolumn{2}{|c|}{241.103} & \multicolumn{2}{|c|}{254.623} \\
\hline
\end{tabular}

Fonte: IBGE/PNADs 1992 a 2007.

Nota: Os dados entre parênteses correspondem aos erros-padrão.

TABELA 5

Características sociodemográficas, geográficas e ocupacionais selecionadas para mães de 15 a 49 anos com, no mínimo, dois filhos, por sexo dos dois primeiros filhos

Brasil - décadas de 1990 e 2000

\begin{tabular}{|c|c|c|c|c|c|c|c|c|}
\hline \multirow{4}{*}{$\begin{array}{l}\text { Características } \\
\text { Sociodemográficas } \\
\text { Número médio de filhos }\end{array}$} & \multicolumn{4}{|c|}{ Década de 1990} & \multicolumn{4}{|c|}{ Década de 2000} \\
\hline & \multirow{3}{*}{$\begin{array}{r}\text { Mesmo } \\
\text { sexo (1) } \\
2,94\end{array}$} & \multirow{3}{*}{$\begin{array}{r}\text { Sexos } \\
\text { opostos (2) } \\
2,85\end{array}$} & \multicolumn{2}{|c|}{ Dif. (3) } & \multirow[t]{2}{*}{$\begin{array}{l}\text { Mesmo } \\
\text { sexo (1) }\end{array}$} & \multirow[t]{2}{*}{$\begin{array}{c}\text { Sexos } \\
\text { opostos (2) }\end{array}$} & \multicolumn{2}{|c|}{ Dif. (3) } \\
\hline & & & & & & & & \\
\hline & & & 0,09 & $\star \star \star$ & 2,68 & 2,61 & 0,06 & $\star \star \star$ \\
\hline Brancas (\%) & 55,10 & 55,80 & $-0,70$ & $\star * *$ & 49,71 & 50,01 & $-0,30$ & $\star \star *$ \\
\hline Unidas (\%) & 85,97 & 86,44 & $-0,46$ & $\star \star \star$ & 82,35 & 83,04 & $-0,69$ & $\star \star \star$ \\
\hline Chefes (\%) & 15,53 & 15,04 & 0,49 & $* * *$ & 22,50 & 21,85 & 0,65 & $* * *$ \\
\hline Idade média corrente & 35,63 & 35,48 & 0,14 & $\star \star \star$ & 36,11 & 35,98 & 0,13 & $\star \star \star$ \\
\hline $\begin{array}{l}\text { Idade média ao ter o(a) } \\
\text { primeiro(a) filho(a) }\end{array}$ & 22,36 & 22,38 & $-0,02$ & $\star * *$ & 22,13 & 22,11 & 0,02 & $\star \star *$ \\
\hline Anos médios de estudo & 5,54 & 5,62 & $-0,07$ & $\star \star \star$ & 6,67 & 6,70 & $-0,03$ & $\star \star \star$ \\
\hline \multicolumn{9}{|l|}{ Geográficas (\%) } \\
\hline \multicolumn{9}{|l|}{ Região de residência } \\
\hline Sul & 15,44 & 15,99 & $-0,55$ & $\star \star \star$ & 14,57 & 14,60 & $-0,03$ & $\star \star \star$ \\
\hline Sudeste & 44,00 & 43,61 & 0,39 & $\star \star \star$ & 42,44 & 42,17 & 0,26 & $\star \star \star$ \\
\hline Norte & 5,03 & 5,02 & 0,01 & $\star \star *$ & 6,67 & 6,65 & 0,02 & $\star \star \star$ \\
\hline Nordeste & 27,80 & 27,76 & 0,04 & $\star \star \star$ & 28,44 & 28,75 & $-0,31$ & $\star \star \star$ \\
\hline Centro-Oeste & 7,73 & 7,61 & 0,12 & $\star \star \star$ & 7,88 & 7,82 & 0,05 & $\star \star *$ \\
\hline \multicolumn{9}{|l|}{ Situação de residência } \\
\hline Urbana & 79,78 & 79,96 & $-0,18$ & $\star \star \star$ & 84,37 & 84,51 & $-0,14$ & $\star \star *$ \\
\hline \multicolumn{9}{|l|}{ Área de residência } \\
\hline Metropolitana & 29,87 & 30,14 & $-0,28$ & $\star \star \star$ & 29,97 & 29,83 & 0,14 & $\star \star \star$ \\
\hline \multicolumn{9}{|l|}{ Ocupacionais } \\
\hline Ativas (\%) & 57,40 & 58,10 & $-0,70$ & $\star \star \star$ & 63,87 & 64,47 & $-0,60$ & $\star \star *$ \\
\hline $\begin{array}{l}\text { Renda média familiar } \\
\text { (em reais de 2001) (4) }\end{array}$ & 482,73 & 491,56 & $-8,83$ & $\star \star \star ~$ & 1681,29 & 1688,22 & $-6,93$ & $\star \star \star *$ \\
\hline $\begin{array}{l}\text { Renda média do não trabalho } \\
\text { (em reais de 2001) (4) (5) }\end{array}$ & 390,63 & 395,88 & $-5,25$ & $\star \star \star *$ & 1304,58 & 1307,68 & $-3,10$ & $\star \star \star$ \\
\hline $\begin{array}{l}\text { Jornada de trabalho de, ao } \\
\text { menos, } 40 \text { horas semanais (\%) (4) }\end{array}$ & 28,68 & 29,51 & $-0,83$ & $\star \star \star ~$ & 33,90 & 34,40 & $-0,50$ & $\star \star \star *$ \\
\hline Observações & 122.175 & 118.928 & & - & 129.282 & 125.341 & & - \\
\hline
\end{tabular}

Fonte: IBGE/PNADs 1992 a 2007.

(1) Mesmo sexo: Mães cujos dois primeiros filhos têm o mesmo sexo.

(2) Sexos opostos: Mães cujos dois primeiros filhos formam um casal.

(3) Teste de diferença: T - C; Hipótese nula: T = C.

(4) Foram consideradas renda zero e jornada de zero horas para quem não trabalhava, por isso, a amostra de mulheres é sempre a mesma, inclusive para essas variáveis.

(5) Renda do não trabalho = renda familiar subtraída da renda de todos os trabalhos da própria mulher.

*** Significativo a $1 \%$; ${ }^{\star \star}$ significativo a $5 \%$. 
em diante), observam-se as diferenças de médias/proporções de algumas variáveis sociodemográficas entre dois grupos de mulheres: aquelas cujos dois primeiros filhos são do mesmo sexo (controle); e as que tiveram um casal de filhos (tratamento).

Verifica-se que a significância de $1 \%$ em todos os testes de diferença de médias reflete, principalmente, a grandeza do tamanho amostral. Tal fato fica claro ao se priorizar a análise da magnitude da diferença, em vez da significância dessa diferença. Todos os indicadores de proporção revelam uma diferença inferior a $1 \%$ entre mulheres-tratamento e controle. Estes fatores sugerem que o efeito do sexo dos dois primeiros filhos sobre a oferta de trabalho feminino seja pouco significativo. E isso é desejável, já que mostra que as mulheres cujos dois primeiros filhos têm o mesmo sexo e aquelas com um casal de filhos apresentam comportamentos semelhantes, inclusive diante do mercado de trabalho e, portanto, se a sua participação no mercado de trabalho sofre influência do sexo dos dois primeiros filhos, isso se dará apenas por meio da fecundidade.

\section{Metodologia}

Para estimar o efeito da fecundidade sobre a oferta de trabalho feminino, nos concentramos em uma variável dependente: participação da mulher na População Economicamente Ativa (PEA), segundo a qual as mulheres foram classificadas como economicamente ativas (incluindo as ocupadas e as desocupadas), ou não economicamente ativas (fora do mercado de trabalho).

Assim, sendo $y_{i}$ uma variável indicadora da participação feminina na PEA e $x_{i}$ o vetor transposto das variáveis explicativas, poderíamos estimar o seguinte modelo linear:

$y_{i}=\beta x_{i}^{\prime}+\varepsilon_{i}$ onde $\beta$ é o vetor de parâmetros a ser estimado e $\varepsilon$ é o erro (independente e distribuído segundo uma distribuição normal, com média zero e variância $\sigma^{2}$ ).

Entretanto, se estimarmos essa equação utilizando como variável explicativa uma variável endógena, como o número de filhos $\left(n_{i}\right)$, por exemplo, o coeficiente $\beta$ estimado para essa variável será viesado, já que provavelmente $E\left(\varepsilon_{i} \mid n_{i}\right) \neq 0$. Uma possibilidade estratégica seria incluir variáveis de controle nesse modelo. Entretanto, há razões para acreditar que a correlação entre as variáveis explicativas e as características não observáveis não seja totalmente captada mesmo após essa inclusão. Segundo Pazello (2006), existem, por exemplo, mulheres que preferem cuidar dos filhos a trabalhar e vice-versa. Essa preferência não é captada por variáveis observáveis. Isso significa que, na equação (1), a variação no número de filhos é endógena, mesmo quando controlada por características observáveis selecionadas.

No caso do nascimento de gêmeos, da ocorrência de natimortos e da preferência dos pais por filhos de ambos os sexos, controlando por algumas variáveis mencionadas mais adiante, a variação no número de filhos pode ser considerada uma variação exógena na fecundidade. Isto porque se espera que os pais não planejem ter gêmeos, nem contem com a perda de um filho depois de sete meses de gestação e também não é possível que escolham o sexo dos filhos tidos. ${ }^{3}$

Entretanto, a estratégia de estimação do primeiro e segundo filhos se difere da estimação do efeito do terceiro ou mais filhos. Por isso, essa seção se divide em duas partes: a primeira trata da estimação do efeito do primeiro e segundo filhos; e a segunda considera a estimação do efeito do terceiro ou mais filhos sobre a participação feminina na PEA.

\footnotetext{
${ }^{3}$ Ressalte-se que a utilização de técnicas de reprodução assistida aumenta a chance do nascimento de gêmeos, mas esse tipo de procedimento, por ser dispendioso, restringe-se às camadas mais abastadas da população. Assim, ao controlarmos os modelos pelas variáveis relacionadas à renda, estamos garantindo a exogeneidade desse evento (PAZELLO, 2006). Além disso, segundo a Sociedade Brasileira de Reprodução Assistida, a sexagem dos embriões é aceita exclusivamente quando há risco de transmissão de doenças genéticas ligadas aos cromossomos sexuais.
} 
A estimação do efeito do primeiro e segundo filhos sobre a participação feminina na PEA

Inicialmente, consideramos a estimação do efeito do primeiro filho. Ao utilizarmos uma variável indicadora da ocorrência ou não de um natimorto (e que, portanto, indica se a mulher não tem filhos ou tem um filho, respectivamente), a variação ocorrida no número de filhos é exógena, não planejada. Assim, com base no fato de que tanto a muIher que teve o filho (controle) quanto aquela que perdeu (tratamento) desejavam a maternidade e considerando a alta correlação entre a ocorrência de natimortos e variáveis determinantes da renda, ${ }^{4}$ o termo $x_{i}^{\prime}$ na equação (1) representa um vetor de variáveis que incluem: a idade corrente da mulher; o quadrado dessa idade; a escolaridade; a presença de cônjuge; a área (se urbana ou não); o tipo de área (se metropolitana ou não) e a região geográfica de residência; clusters por unidade da Federação; a renda do não trabalho (renda familiar exclusive a renda da própria mulher); o décimo da renda familiar ao qual a mulher pertence; e quatro variáveis de características domiciliares (se possui rede geral de água, pelo menos um banheiro, serviço de coleta de lixo e iluminação elétrica). Além dessas variáveis, como estimamos modelos que contêm vários anos (devido à raridade do evento natimorto), há também uma variável indicadora do ano em que cada pesquisa foi realizada.

A hipótese central das estimativas do efeito de filhos é a seguinte: assumimos que os fatores que afetam a probabilidade de ocorrência de natimortos (relacionados à renda) não afetem a probabilidade de participação da mulher na PEA por outros meios que não pela variação na fecundidade (idem para o nascimento de gêmeos).
Os modelos foram estimados sem utilizar o peso de expansão e adicionando clusters segundo as unidades da Federação, de forma a considerar a lógica de estratificação amostral das PNADs. A opção pela não utilização dos pesos deve-se, em primeiro lugar, ao fato de que nossas amostras são compostas de dados de vários anos empiIhados. Em segundo lugar, não estimamos parâmetros de população, mas sim parâmetros individuais (ou seja, o objetivo não é estimar a taxa de atividade dessas mulheres, mas sim estimar como os filhos afetam a probabilidade delas estarem no mercado de trabalho). Em terceiro lugar, incluímos no modelo variáveis-controle para as características individuais, como, por exemplo, raça e educação (WINSHIP; RADBILL, 1994). Além disso, como nossa amostra é bastante restrita (mulheres de 15 a 49 anos e com, no máximo, um filho), não é aconselhável a utilização de pesos individuais presentes nos microdados das PNADs.

Como a variável-resposta $\left(y_{i}\right)$ é binária, os modelos são estimados segundo uma função logística. No modelo logístico, cada coeficiente fornece o impacto de uma variação ocorrida nas variáveis explicativas sobre a média da variável dependente, o que é conhecido como efeito marginal. Assim, com base no $\beta$ da variável indicadora da ocorrência de natimortos $\left(\right.$ nat $_{i}$ ), obtemos o efeito marginal dessa variável (e, portanto, da ausência de filhos) sobre a probabilidade de a mulher fazer parte da PEA:

$$
\frac{\partial E\left[y_{i} / \text { nat }_{i}\right]}{\partial \text { nat }_{i}}=\frac{e^{x_{i} \beta}}{\left[1+e^{x_{i} \beta}\right]^{2}} \times \beta_{\text {nat }}=F\left(x_{i}^{\prime} \beta\right) \times\left[1-F\left(x_{i}^{\prime} \beta\right)\right] \times \beta_{\text {nat }}
$$

Quanto à interpretação do efeito estimado com base nessa equação, temos que um efeito marginal positivo da variável nat sugere que as mulheres sem filhos apresentam maior probabilidade de pertencerem à

\footnotetext{
${ }^{4}$ Além da baixa renda, alguns comportamentos da mulher durante a gestação aumentam a probabilidade de ocorrência de natimortos, como, por exemplo, o hábito de fumar (BROSKY, 1995; HÖGBERG; CNATTINGIUS, 2007), o consumo de bebidas alcoólicas ou drogas, em geral (KESMODEL et. al., 2003) ou o consumo excessivo de café (WISBORG et. al., 2003). Mulheres que apresentam obesidade, diabetes, hipertensão, doença renal e distúrbios de tireoide também têm o risco de natimorto aumentado (ALLEN et. al., 2004; ELLER et. al., 2006; MACINTOSH, 2006). Não temos como controlar nossas estimativas do efeito do primeiro filho sobre a participação feminina na PEA no que se refere a todas as características associadas ao evento natimorto. Podemos, de acordo com as informações disponíveis, verificar o quão semelhantes as mulheres sem filhos (que tiveram natimorto) são em relação àquelas com filhos (que não tiveram). E é desejável que elas sejam muito parecidas, já que é um estudo do tipo caso-controle.
} 
PEA em relação às mães de um filho. Por exemplo, um efeito marginal da variável indicadora da ocorrência de natimortos de $3 \%$ sobre a participação das mães significa que as mulheres sem filhos têm probabilidade $3 \%$ superior de estarem inseridas no mercado de trabalho quando comparadas àquelas que têm um filho. ${ }^{5}$

O exercício foi realizado nas duas amostras (todas as mulheres e apenas as unidas de 15 a 49 anos) e para as duas décadas (1990 e 2000). No final, temos quatro estimativas do efeito médio do tratamento (ter tido algum natimorto e não ter filhos).

Com o objetivo de dar maior robustez aos resultados, também realizamos pareamentos probabilísticos. Segundo Pazello e Fernandes (2004), por meio desse procedimento, pareamos indivíduos similares em características observáveis, mas que pertencem a grupos diferentes (tratamento e controle). A ideia implícita nesse método está no fato de que, embora não tenhamos um contra-factual (ou seja, não há possibilidade de uma mesma mulher pertencer, concomitantemente, ao grupo tratamento e ao de controle), podemos criar uma estimativa dele. Assim, estimamos uma regressão logística de tal forma que obtemos, para cada mulher, sua probabilidade de pertencer ao grupo tratamento (ou seja, sua probabilidade de ter, pelo menos, um natimorto).

Baseados nessa estimativa, selecionamos, para cada mulher-tratamento, uma (ou mais) mulher(es) do grupo controle cujo escore de propensão seja o mais próximo possível.

Existem vários procedimentos de identificação dessas mulheres-controle e mulheres-tratamento com escores de propensão semelhantes. Pode-se identificar, por exemplo, pares de mulheres dos grupos controle e tratamento que tenham exatamente o mesmo escore. Fazendo isso, entretanto, corremos o risco de não encontrar mulheres-controle para todas as mulheres-tratamento e, dado que o evento natimorto é raro, isso não é desejável. Nesse estudo, pareamos pelo método do vizinho mais próximo (SMITH, 1997).

Esse método permite escolher quantos vizinhos forem desejados, desde que o tamanho da amostra seja suficiente. Ou seja, é possível escolher quantas mulheres servirão de controle para cada mulher do grupo tratamento, sendo que, ao utilizarmos apenas uma mulher como controle, é como se estivéssemos atribuindo peso 1 a ela e peso zero às demais controles (PAZELLO; FERNANDES, 2004). Na realidade, segundo Smith (1997), quanto mais controles estão disponíveis para cada unidade do grupo tratamento, melhor. Isto porque selecionar mais de um controle como par para cada unidade do grupo tratamento aumenta a eficiência do procedimento, além de poder reduzir o viés.

Ainda segundo Smith (1997), o pareamento constitui um instrumental especialmente útil se a condição que define os indivíduos como tratamento for um evento raro na população e os controles forem numerosos. Nesse artigo, assim como $\mathrm{Pa}-$ zello e Fernandes (2004), realizamos seis pareamentos com 1, 5 e 10 vizinhos e, em todos os casos, testamos uma distância máxima entre os escores de propensão de mulheres-controle e tratamento de $0.0001 \mathrm{e}$ de 0.00001 (valores testados por DEHEJIA E WAHBA, 2002). Também selecionamos um suporte comum no qual delimitamos um mesmo intervalo de valores para os escores de propensão de mulheres-tratamento e controle. Além disso, utilizamos pareamento com reposição, ou seja, uma mulher do grupo controle pode ser pareada com mais de uma mulher do grupo tratamento. Para Dehejia e Wahba (2002), essa escolha minimiza a distância dos escores de propensão entre os grupos controle e tratamento, reduzindo o viés da amostra.

Ao estimarmos o escore de propensão, assumimos que a probabilidade de uma mulher da amostra ser tratamento (ou seja, ter tido algum natimorto) deva

\footnotetext{
5 Como estamos interessados no efeito do primeiro filho (e não da ausência de filhos) sobre a participação das mães no mercado de trabalho, na análise dos resultados, apenas invertemos o sinal do efeito marginal encontrado no modelo estimado.
} 
respeitar uma função logística, cujas variáveis independentes sejam, na medida do possível, ${ }^{6}$ as mesmas da equação (1), acrescidas de algumas interações entre essas variáveis incluídas nos modelos. A inclusão dessas interações se faz necessária para que as diferenças entre os grupos tratamento e controle sejam zeradas e, assim, a propriedade de balanceamento do escore de propensão seja satisfeita (DEHEJIA; WAHBA, 2002; PAZELLO; FERNANDES, 2004).

Ao todo, estimamos quatro modelos de escores de propensão, um para cada amostra (todas as mulheres e apenas as unidas de 15 a 49 anos) nas décadas de 1990 e 2000.

Com o novo conjunto de mulheres resultante do pareamento, re-estimamos mais seis vezes a equação (1), variando a distância máxima determinada entre os escores dos pares tratamento-controle e o número de vizinhos. Isso significa que, no total, além dos quatro efeitos do primeiro filho sobre a participação das mães do modelo original (sem pareamento), temos mais 24 (4x6) efeitos estimados com base no escore de propensão. Dado que a diferença fundamental entre as estimativas obtidas antes e depois do pareamento está no processo de ponderação, essa estratégia funciona como um teste de robustez dos resultados (PAZELLO; FERNANDES, 2004). Além disso, esses modelos servirão de base para avaliar em que medida o modelo sem pareamento é viesado ou não.

No caso da estimação do efeito do segundo filho sobre a participação feminina na PEA (utilizando o nascimento de gêmeos como proxy para a fecundidade), também realizamos os mesmos procedimentos da estimação do efeito do primeiro filho descrito anteriormente.

Tendo em vista que a ocorrência de natimortos está associada a condições de pobreza, enquanto o nascimento de gêmeos relaciona-se a melhores condições de vida, a estimação do efeito do segundo filho se difere da estimação anterior pela não inclusão das variáveis referentes à infraestrutura domiciliar nos modelos. Isto porque são variáveis de infraestrutura básica, justificáveis, portanto, para diferenciar mulheres em piores condições de vida.

A interpretação do efeito estimado é análoga àquela do efeito do primeiro filho sobre a participação feminina no mercado de trabalho, de forma que temos que um efeito marginal negativo da variável 'gem' sugere que as mães de gêmeos apresentam menor probabilidade de pertencerem à $\mathrm{PEA}$ em relação àquelas com um filho.

Também realizamos os mesmos exercícios de pareamento nas três amostras (todas as mães de 15 a 49 anos de idade, apenas as unidas e somente as mães de filhos com, no máximo, dois anos de idade) e para as duas décadas (1990 e 2000). Ou seja, temos 42 estimativas do efeito médio do tratamento (ter tido gêmeos): seis dos modelos originais (sem pareamento) e 36 dos modelos realizados com base no escore de propensão.

\section{A estimação do efeito do terceiro ou mais filhos sobre a participação feminina na PEA}

Como essa estimação baseia-se em um instrumento (a preferência dos pais por filhos de ambos os sexos) e não em uma proxy para a fecundidade, a estimativa do efeito de um terceiro (ou mais) filho deve ser feita em dois estágios. Primeiro, estimamos o efeito da preferência dos pais por filhos de ambos os sexos sobre a probabilidade de a mulher ter mais de dois filhos (primeiro estágio da estimação) e, em seguida, estimamos o efeito de um filho adicional a partir do terceiro sobre a participação da mulher na PEA (segundo estágio).

Primeiro estágio: estimando o efeito da preferência dos pais por filhos de ambos os sexos sobre a probabilidade de se ter mais de dois filhos

Sendo $m d_{i}$ uma variável binária que assume valor 1 , se a mulher tem mais de dois filhos, e valor zero, se tem exatos dois

\footnotetext{
${ }^{6}$ Excluída, claro, a variável que indica se a mulher teve ou não um natimorto, que na estimação do escore de propensão passa a ser a variável-resposta.
} 
filhos, estimamos o seguinte modelo de regressão logística:

$E\left[m d_{i} / z_{i}\right]=1\left[F\left(z_{i}^{\prime} \beta\right)\right]+0\left[1-F\left(z_{i}^{\prime} \beta\right)\right]$

Na qual: $F\left(z_{i}^{\prime} \beta\right)=e^{z_{i}^{\prime} \beta} /\left[1+e^{z_{i}^{\prime} \beta}\right]$

Nessa equação, o vetor $z_{i}^{\prime}$ inclui a variável instrumental indicadora do sexo dos dois primeiros filhos (assumindo valor 1, se são do mesmo sexo, e valor zero, se são uma menina e um menino) e as variáveis inseridas como controles: idade corrente da mãe; idade ao quadrado; escolaridade; presença de cônjuge; área de residência (se urbana ou não); tipo de área (se metropolitana ou não); região geográfica e clusters por UFs; renda do não trabalho (renda familiar exclusive a renda da própria mulher); décimo da renda familiar ao qual a mulher pertence; presença de filhos ou filhas com até dois anos de idade, entre 3 e 6 anos e entre 7 e 12 anos; sexo do primeiro e segundo filhos; e uma variável indicadora do ano em que cada pesquisa foi realizada.

Segundo estágio: estimando o efeito de um filho adicional a partir do terceiro filho sobre a participação feminina no mercado de trabalho

Essa estimativa do efeito da variável instrumental (que indica se os dois primeiros filhos são do mesmo sexo) sobre a probabilidade de nascimento de um filho adicional a partir do terceiro (obtida no primeiro estágio) passa, então, a representar uma variação exógena na fecundidade em relação à oferta de trabalho das mães. Portanto, essa estimativa, inserida no modelo de oferta de trabalho feminino, fornece o efeito do terceiro (ou mais) filho sobre a participação das mães na PEA.

Assim, sendo $y_{i}$ uma medida de oferta de trabalho (participação na PEA) e $x_{i}$ o vetor de variáveis explicativas que incluem, além da estimativa da probabilidade de nascimento de um terceiro filho obtida no primeiro estágio, as mesmas variáveis-controle do modelo de fecundidade (primeiro estágio), estimamos a seguinte regressão logística (segundo estágio):

$E\left[y_{i} / x_{i}\right]=1\left[F\left(x_{i}^{\prime} \beta\right)\right]+0\left[1-F\left(x_{i}^{\prime} \beta\right)\right]$

Na qual: $F\left(x_{i}^{\prime} \beta\right)=e^{x_{i}^{\prime} \beta} /\left[1+e^{x_{i}^{\prime} \beta}\right]$
Novamente, a interpretação desse efeito é análoga às anteriores: um efeito marginal negativo da variável ' $m d$ ' sugere que as mães de três ou mais filhos apresentam menor probabilidade de participarem da PEA em relação àquelas com dois filhos.

Devemos fazer uma ressalva para a estimação do efeito do terceiro ou mais filhos sobre a participação feminina na PEA. Chamamos a atenção para o fato de que existem pais que não revelam na fecundidade uma preferência por filhos de ambos os sexos, uma vez que há mulheres que tiveram um casal de filhos e, ainda assim, tiveram mais filhos, da mesma forma como existem mulheres que, embora sejam mães de apenas dois filhos do mesmo sexo, não tiveram outro. Isso traz algumas particularidades na estrutura de um estudo tipo caso-controle, de modo que, na estimativa do efeito do terceiro filho, as mulheres-tratamento são apenas aquelas com mais de dois filhos, sendo os dois primeiros do mesmo sexo, e as controles compreendem aquelas com apenas dois filhos, sendo esses um menino e uma menina (as compliers), o que faz com que o efeito de um filho adicional a partir do terceiro seja um efeito médio local do tratamento.

Lembramos que esse exercício foi realizado nas duas amostras de mulheres com, no mínimo, dois filhos (todas as mães e apenas as unidas de 15 a 49 anos) nas duas décadas (1990 e 2000). Ou seja, temos quatro estimativas do efeito médio local do tratamento (ter tido três ou mais filhos, sendo os dois primeiros do mesmo sexo).

Diferentemente das estimações do efeito do primeiro e do segundo filhos sobre a participação das mulheres na PEA, aqui não utilizamos técnicas de pareamento, especialmente porque, por não estarmos tratando de um evento raro (ter dois filhos do mesmo sexo), temos quase a mesma quantidade de mulheres-tratamento e mulheres-controle, o que não constitui cenário adequado à aplicação da referida técnica. Além disso, pelo fato de ser um evento bastante comum na população, as mulheres-tratamento não constituem um grupo com características tão específicas e diferenciadas do restante da amostra (as mulheres-controle), tornando desnecessária 
a realização de pareamentos como forma de validar os resultados encontrados.

\section{Resultados}

Com relação aos modelos logitos dos escores de propensão, utilizados na estimação do efeito do primeiro e segundo filhos sobre a participação feminina na PEA (resultados não apresentados), vale dizer que todas as diferenças entre as mulheres do grupo controle e aquelas do grupo tratamento (observadas nas Tabelas 2 e 3), existentes nas amostras antes do pareamento, tornaram-se não significativas após o pareamento. Esta é uma evidência de que o pareamento, de fato, reduziu o viés das amostras.

\section{O efeito do primeiro filho sobre a participação feminina na PEA}

O efeito marginal do primeiro filho sobre a participação na PEA, para as duas amostras de mulheres, nas décadas de 1990 e de 2000, é apresentado na Tabela 6. Primeiramente, destaca-se o fato de que todos os efeitos são negativos, indicando que o nascimento do primeiro filho tende a diminuir a probabilidade de a mãe fazer parte da PEA.
Na Tabela 6, a linha denominada "Original" contém o efeito marginal (ou seja, a variação percentual observada na participação feminina na PEA em função do nascimento do primeiro filho), estimado com base nas amostras não pareadas de mulheres, enquanto nas demais linhas estão os efeitos baseados nas amostras pós-pareamento. Considerando-se que o pareamento contribuiu para a redução do viés amostral e, mais que isso, que a utilização de mais de um controle para cada tratamento é mais eficiente em termos do melhor aproveitamento das informações disponíveis, extraímos a média dos efeitos do primeiro filho encontrados nos modelos pareados com 5 e 10 vizinhos (ambos os calipers), para interpretarmos a nossa estimativa do efeito marginal do primeiro filho sobre a participação das mães na PEA.

Assim, na Tabela 6, verifica-se que, nos anos 1990, o primeiro filho reduz a participação das mulheres na PEA em 8,25\%, para aquelas de 15 a 49 anos, e em $9 \%$, para as unidas. Isso significa dizer que o fato de terem um filho faria com que a participação dessas mulheres na PEA passasse, respectivamente, de uma média de $64,62 \%$ para $59,29 \%$ e de $59,76 \%$ para $54,38 \%$. Pazello

TABELA 6

Efeito marginal do primeiro filho sobre a participação feminina na PEA para mulheres de 15 a 49 anos, segundo método utilizado

Brasil - décadas de 1990 e 2000

\begin{tabular}{|c|c|c|c|c|c|}
\hline & \multirow[b]{2}{*}{ Método } & \multicolumn{2}{|c|}{ Década de 1990} & \multicolumn{2}{|c|}{ Década de 2000} \\
\hline & & Todas & $\begin{array}{l}\text { Apenas } \\
\text { unidas }\end{array}$ & Todas & $\begin{array}{c}\text { Apenas } \\
\text { unidas }\end{array}$ \\
\hline \multirow{2}{*}{ Original } & & $-9,4011$ & $-9,1273$ & $-6,6948$ & $-7,9487$ \\
\hline & & $(0,0000)$ & $(0,0000)$ & $(0,0000)$ & $(0,0000)$ \\
\hline \multirow{6}{*}{ Caliper, $\delta=0,0001$} & \multirow{2}{*}{ Pareamento com 1 vizinho } & $-8,6963$ & $-7,4782$ & $-5,9413$ & $-5,3065$ \\
\hline & & $(0,0000)$ & $(0,0010)$ & $(0,0000)$ & $(0,0010)$ \\
\hline & \multirow{2}{*}{ Pareamento com 5 vizinhos } & $-8,1432$ & $-8,2998$ & $-6,1450$ & $-6,2418$ \\
\hline & & $(0,0000)$ & $(0,0000)$ & $(0,0000)$ & $(0,0000)$ \\
\hline & \multirow{2}{*}{ Pareamento com 10 vizinhos } & $-8,4870$ & $-8,4256$ & $-6,0336$ & $-6,6807$ \\
\hline & & $(0,0000)$ & $(0,0000)$ & $(0,0000)$ & $(0,0000)$ \\
\hline \multirow{6}{*}{ Caliper, $\delta=0,00001$} & \multirow{2}{*}{ Pareamento com 1 vizinho } & $-8,2434$ & $-8,5306$ & $-6,5451$ & $-5,8709$ \\
\hline & & $(0,0000)$ & $(0,0000)$ & $(0,0000)$ & $(0,0000)$ \\
\hline & \multirow{2}{*}{ Pareamento com 5 vizinhos } & $-7,9045$ & $-9,4568$ & $-6,6746$ & $-6,4771$ \\
\hline & & $(0,0000)$ & $(0,0000)$ & $(0,0000)$ & $(0,0000)$ \\
\hline & \multirow{2}{*}{ Pareamento com 10 vizinhos } & $-8,4726$ & $-9,8149$ & $-6,7634$ & $-7,1861$ \\
\hline & & $(0,0000)$ & $(0,0000)$ & $(0,0000)$ & $(0,0000)$ \\
\hline
\end{tabular}

Fonte: IBGE/PNADs 1992 a 2007.

Nota: Valor-p entre parênteses. 
e Fernandes (2004) encontraram resultados que apontam nessa mesma direção. Em uma amostra de mulheres urbanas de 15 a 52 anos de idade na década de 1990, os autores estimaram que a probabilidade média das mulheres sem filhos de participarem da PEA reduziria 10,28 pontos percentuais ao terem um filho, passando de $65,6 \%$ para $55,32 \%$.

Já na década de 2000, o primeiro filho reduz a participação das mulheres sem filhos na PEA em 6,4\% (contra $8,25 \%$ da década anterior), para aquelas de 15 a 49 anos, e em 6,65\% (contra 9\%), para as unidas. Tais números indicam que se as mulheres sem filhos na década de 2000 resolvessem ter um filho, sua participação na PEA seria reduzida de $67,83 \%$ para $62,79 \%$, na amostra de 15 a 49 anos, e de $65,68 \%$ para $60,57 \%$, se consideramos apenas as unidas nesta faixa etária.

\section{$O$ efeito do segundo filho sobre a participação feminina na PEA}

A Tabela 7 reporta o efeito marginal do segundo filho sobre a probabilidade de as mulheres pertencerem à PEA, nas três amostras de mulheres nas décadas de 1990 e 2000 (todas as mães de 15 a 49 anos, apenas as unidas e apenas aquelas que têm filhos com, no máximo, dois anos). Novamente, o fato de todos os efeitos serem negativos sugere que ter um segundo filho (assim como no caso do primeiro filho) tende a reduzir a probabilidade feminina de participação na PEA.

Assim como na estimação do efeito do primeiro filho, interpretamos a média dos efeitos do segundo filho estimados nos modelos pareados com 5 e 10 vizinhos (ambos os calipers), como sendo a nossa estimativa do efeito marginal do segundo filho sobre a participação das mães na PEA.

Dessa forma, tendo em vista que na Tabela 7 - em se tratando das amostras contendo todas as mães de 15 a 49 anos de idade ou apenas as unidas na década de 1990 - tanto a magnitude como a significância dos efeitos estimados nas amostras pareadas se reduzem ao utilizarmos mais vizinhos no pareamento (na amostra com todas as mães, com caliper $=0,0001$, por exemplo, o efeito marginal passa de $-3,27 \%$ para $-2,59 \% \mathrm{com}$

TABELA 7

Efeito marginal do segundo filho sobre a participação feminina na PEA para mães de 15 a 49 anos, segundo método utilizado

Brasil - décadas de 1990 e 2000

\begin{tabular}{|c|c|c|c|c|c|c|c|}
\hline \multirow{2}{*}{ 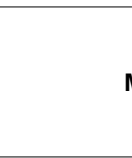 } & & \multicolumn{3}{|c|}{ Década de 1990} & \multicolumn{3}{|c|}{ Década de 2000} \\
\hline & Método & Todas & Apenas & $\begin{array}{l}\text { Com filhos de, } \\
\text { no máximo, }\end{array}$ & Todar & Apenas & $\begin{array}{l}\text { Com filhos de, } \\
\text { no máximo, }\end{array}$ \\
\hline \multirow{2}{*}{ Original } & & $-3,4216$ & $-1,2308$ & $-10,6349$ & $-3,1992$ & $-3,9026$ & $-6,7779$ \\
\hline & & $(0,0390)$ & $(0,5460)$ & $(0,0010)$ & $(0,0050)$ & $(0,0120)$ & $(0,0210)$ \\
\hline \multirow{6}{*}{$\begin{array}{l}\text { Caliper, } \\
\delta=0,0001\end{array}$} & Pareamento & $-4,3262$ & $-2,9634$ & $-10,0822$ & $-2,1786$ & $-1,6751$ & $-7,4817$ \\
\hline & com 1 vizinho & $(0,0650)$ & $(0,3380)$ & $(0,0420)$ & $(0,0930)$ & $(0,4660)$ & $(0,0380)$ \\
\hline & Pareamento & $-3,2702$ & $-2,7310$ & $-11,1748$ & $-3,2287$ & $-3,3404$ & $-7,3950$ \\
\hline & com 5 vizinhos & $(0,0540)$ & $(0,1290)$ & $(0,0050)$ & $(0,0130)$ & $(0,0440)$ & $(0,0180)$ \\
\hline & Pareamento & $-2,5850$ & $-2,3324$ & $-10,8089$ & $-2,9900$ & $-3,3949$ & $-7,8564$ \\
\hline & com 10 vizinhos & $(0,1310)$ & $(0,2120)$ & $(0,0020)$ & $(0,0190)$ & $(0,0150)$ & $(0,0090)$ \\
\hline \multirow{6}{*}{$\begin{array}{l}\text { Caliper, } \\
\delta=0,00001\end{array}$} & Pareamento & $-4,4692$ & $-2,9575$ & $-10,7512$ & $-2,2480$ & $-1,8178$ & $-8,0192$ \\
\hline & com 1 vizinho & $(0,0590)$ & $(0,3340)$ & $(0,0270)$ & $(0,0840)$ & $(0,4210)$ & $(0,0320)$ \\
\hline & Pareamento & $-3,4815$ & $-2,7930$ & $-12,3818$ & $-3,2305$ & $-3,3200$ & $-7,5093$ \\
\hline & com 5 vizinhos & $(0,0430)$ & $(0,1210)$ & $(0,0020)$ & $(0,0120)$ & $(0,0410)$ & $(0,0180)$ \\
\hline & Pareamento & $-2,7827$ & $-2,3085$ & $-12,4200$ & $-2,7864$ & $-3,3043$ & $-8,1324$ \\
\hline & com 10 vizinhos & $(0,1090)$ & $(0,2120)$ & $(0,0010)$ & $(0,0300)$ & $(0,0170)$ & $(0,0090)$ \\
\hline
\end{tabular}

Fonte: IBGE/PNADs 1992 a 2007.

Nota: Valor-p entre parênteses. 
valor-p aumentando de 0,054 para 0,131, respectivamente), consideramos não haver efeito negativo de filhos sobre a participação feminina naquela década.

Pazello (2006) encontrou que, na década de 1990, o nascimento de gêmeos reduzia a probabilidade de uma mulher de 15 a 40 anos fazer parte da PEA em $1,27 \%$ (significativo a $5 \%$ ) e se ela for unida, esse decréscimo seria de 2,44\% (também significativo a $5 \%$ ). Mesmo que tenhamos utilizado grupos etários e especificações dos modelos diferentes, os efeitos apontam para a mesma direção dos efeitos do segundo filho sobre a participação feminina na PEA estimados por nós, já que, embora significativos, os efeitos obtidos por Pazello (2006) têm magnitudes bastante reduzidas.

Esse resultado pode ser reflexo do próprio uso do nascimento de gêmeos como proxy para a fecundidade. É possível que as famílias que tiveram gêmeos na primeira gravidez ajustem no longo prazo essa variação exógena da fecundidade, de forma que o evento "gêmeos" tenha um impacto significativo sobre a decisão de trabalho materna, mas esse impacto diminua ao longo do tempo (PAZELLO, 2006). O fato de não termos encontrado qualquer efeito de um segundo filho pode também ser função de uma economia de escala relacionada à criação de dois filhos ao mesmo tempo. Por esse motivo, foram também estimados modelos de curto prazo, considerando apenas mães de 15 a 49 anos que têm filhos com, no máximo, dois anos. Selecionamos esse corte etário de idade dos filhos para efeitos de comparação com outros estudos (PAZELLO, 2006) e, além disso, nosso objetivo principal é estimar o efeito da fecundidade (não o efeito de características dos filhos, como idade e sexo) sobre a decisão de oferta de trabalho feminino.

É importante enfatizar que, embora exista um efeito-idade dos filhos sobre a decisão de trabalho das mulheres (SOARES, 2002), esse não constitui objetivo do presente artigo. No caso da estimação do efeito do segundo filho, realizamos um corte de idade dos filhos pelo fato de o nascimento de gêmeos provocar economia ou deseconomia de escala, dependendo se estamos nos referindo a curto ou longo prazo. E, dado que essas duas forças competem no sentido de anular o efeito do segundo filho, nossa intenção não foi verificar especificamente o efeito da idade dos filhos sobre o trabalho feminino, mas sim verificar que a não existência do efeito do segundo filho poderia dever-se a essa particularidade do uso de gêmeos como proxy para a fecundidade.

$\mathrm{Na}$ Tabela 7 (coluna 3), verifica-se que o segundo filho reduzia em $11,7 \%$ a participação das mães de filhos pequenos (dois anos, no máximo) na PEA, na década de 1990. Isso significa dizer que o fato de terem gêmeos diminuiria a participação dessas mulheres na PEA de uma média de $43,44 \%$ (já bem inferior àquela observada considerando-se todas as mulheres de 15 a 49 anos, que era de $57,58 \%$ - Tabela 3) para $38,36 \%$.

Pazello (2006) obteve resultados semelhantes aos aqui encontrados, utilizando igualmente as PNADs brasileiras dos anos 1990. A autora também verificou um efeito negativo significativo dos gêmeos apenas no curto prazo, com magnitude similar ao nosso: da ordem de $-10,10 \%$.

Análises semelhantes às realizadas para os anos 1990 podem ser feitas para 2000. Considerando-se todas as mães de 15 a 49 anos (Tabela 7), observamos que, embora na década de 1990 um segundo filho parecia não afetar a participação feminina na PEA, nos anos 2000 , o fato de ter um segundo filho diminui em $3,06 \%$ a probabilidade de uma mulher pertencer à PEA. Tal fato também se repetiu com as mães unidas. $O$ efeito que não existia na década anterior passou a ser significativo e com magnitude suavemente superior à de todas as mães: na década de 2000 , o segundo filho reduz em 3,34\% a probabilidade de a mãe unida participar da PEA.

A Tabela 7 (coluna 6) também mostra que, assim como na década anterior, apenas os filhos com, no máximo, dois anos afetam negativa e significativamente a inserção feminina no mercado de trabalho. Observamos, entretanto, que o efeito do segundo filho sobre a participação na PEA das mães de um filho pequeno se reduz entre uma década e outra. Enquanto nos anos 1990 um 
segundo filho diminuía em $11,7 \%$ a probabilidade de uma mãe com filhos pequenos ser economicamente ativa, nos 2000 essa redução é de $7,72 \%$.

Vale destacar, entretanto, que estimar o efeito do segundo filho utilizando o nascimento de gêmeos há, no máximo, dois anos como proxy para a fecundidade pode acarretar uma superestimação desse efeito. Isto porque ter filhos gêmeos não é a mesma coisa que ter dois filhos em momentos distintos. Segundo Pazello (2006), no curto prazo, deve haver alguma deseconomia de escala pelo fato de a mulher ter dois filhos de uma só vez e, portanto, isso significa que o efeito do segundo filho estimado com base no nascimento de gêmeos estaria captando também o próprio efeito de se ter gêmeos sobre a participação das mães no mercado. Assim, devemos ressaltar que os efeitos do segundo filho sobre a participação feminina na PEA estimados usando os gêmeos como proxy devem ser interpretados como um valor-limite superior do possível impacto de um segundo filho não planejado.

Dessa forma, a superioridade do efeito negativo do segundo filho em relação ao efeito do primeiro, em ambas as décadas, pode ser justificada pela captação do próprio efeito de ter gêmeos. Portanto, esse resultado não necessariamente contraria a ideia de que o primeiro filho seja o que afeta mais negativamente a inserção feminina no mercado de trabalho, como apontado por Lérida (2006).

O efeito de um filho adicional a partir do terceiro sobre a participação feminina na PEA

Na Tabela 8, apresentamos as estimativas do efeito marginal do nascimento de um filho adicional a partir do terceiro sobre a probabilidade de as mulheres constituírem parte da PEA com base em modelagens distintas, para as duas amostras de mulheres nas décadas de 1990 e 2000.

$\mathrm{Em}$ todos os casos, quando o efeito estimado é significativo, seu sinal é negativo, indicando que um terceiro ou mais filhos, assim como o primeiro e o segundo filhos, diminui a probabilidade de as mães serem economicamente ativas, em ambas as décadas.

Analisando os modelos MQO endógeno e Logit endógeno, verificamos que, ao inserir a variável indicadora de mais de dois filhos diretamente nos modelos de oferta de trabalho, um terceiro filho parece não afetar a probabilidade de a mãe estar inserida no mercado de trabalho (em termos não apenas da significância dos efeitos encon-

TABELA 8

Efeito marginal de um filho adicional a partir do terceiro filho sobre a probabilidade de as mães participarem da PEA para mulheres de 15 a 49 anos com, pelo menos, dois filhos Brasil - décadas de 1990 e 2000

\begin{tabular}{|c|c|c|c|c|c|c|}
\hline \multirow{2}{*}{ Década } & \multirow{2}{*}{$\begin{array}{l}\text { Amostra de } \\
\text { mulheres }^{1}\end{array}$} & \multirow{2}{*}{$\begin{array}{c}\text { Estimativa } \\
\text { ingênua (1) }\end{array}$} & \multicolumn{2}{|c|}{ MQO } & \multicolumn{2}{|c|}{ Logit } \\
\hline & & & Endógeno (2) & VI & Endógeno (2) & VI \\
\hline \multirow{4}{*}{1990} & \multirow{2}{*}{ Todas } & $-9,4513$ & 0,3174 & $-13,6976$ & 0,3500 & $-5,5191$ \\
\hline & & $(0,2020)$ & $(0,4510)$ & $(0,1850)$ & $(0,4380)$ & $(0,0000)$ \\
\hline & \multirow{2}{*}{ Apenas unidas } & $-7,0680$ & 0,0924 & $-10,1001$ & 0,1193 & $-4,6430$ \\
\hline & & $(0,3610)$ & $(0,8480)$ & $(0,3630)$ & $(0,8150)$ & $(0,0010)$ \\
\hline \multirow{4}{*}{2000} & \multirow{2}{*}{ Todas } & $-5,7603$ & 0,0885 & $-8,4245$ & 0,1258 & $-5,9185$ \\
\hline & & $(0,1520)$ & $(0,7500)$ & $(0,1120)$ & $(0,6720)$ & $(0,0000)$ \\
\hline & \multirow{2}{*}{ Apenas unidas } & $-6,4359$ & $-0,0270$ & $-9,1026$ & 0,0031 & $-4,8886$ \\
\hline & & $(0,1020)$ & $(0,9200)$ & $(0,0850)$ & $(0,9920)$ & $(0,0020)$ \\
\hline
\end{tabular}

Fonte: IBGE/PNADs 1992 a 2007

(1) Nesse caso, o efeito marginal do terceiro filho sobre o status ocupacional das mães foi obtido pela razão entre o efeito margina da variável indicadora de filhos do mesmo sexo no modelo de oferta de trabalho e o efeito marginal dessa mesma variável no modelo de fecundidade; sendo ambos os modelos logitais.

(2) Nesse caso, o efeito marginal do terceiro filho sobre o status ocupacional das mães foi obtido pela inserção direta da variável que indica se a mulher tem dois ou mais de dois filhos no modelo de oferta de trabalho.

Nota: Valor-p entre parênteses. 
trados, mas também da sua magnitude). Isto porque, dada a endogeneidade do modelo, outras variáveis devem estar camuflando a existência desse possível efeito.

Ao estimarmos o efeito marginal de um terceiro ou mais filhos sobre a oferta de trabalho feminina por meio do modelo Logit $\mathrm{VI}$, há importantes diferenças entre o MQO e o Logit. Quando utilizamos uma regressão linear, embora o efeito de filhos, em geral, seja bastante superior (em magnitude) à estimativa na qual empregamos uma regressão logística, nos modelos MQO o efeito de filhos não é significativo a $5 \%$ em quaisquer amostras nos dois períodos analisados. Já no modelo Logit VI, o efeito negativo de filhos aparece em ambas as amostras.

Nossas estimativas do efeito de um terceiro ou mais filhos sobre a participação feminina no mercado de trabalho baseiam-se no modelo Logit $\mathrm{VI}$ (de forma que os demais modelos foram estimados para efeito de comparação).

Assim, verificamos que, na década de 1990, um terceiro (ou mais) filho diminui a probabilidade de a mãe ser economicamente ativa: $5,52 \%$ para as mulheres de 15 a 49 anos; e 4,64\% para aquelas unidas nesse mesmo grupo etário (Tabela 8 , última coluna). Também nos anos 2000 , observamos tendência semelhante entre as amostras. Além disso, entre as décadas de 1990 e de 2000 , como a magnitude dos efeitos aumentou suavemente nas duas amostras, o nascimento de um filho adicional a partir do terceiro filho parece ter afetado, no mínimo, da mesma maneira as mulheres ao longo dessas duas décadas.

\section{Considerações finais}

Nesse artigo utilizamos duas proxies (a ocorrência de natimortos e o nascimento de gêmeos) e um instrumento (a preferência dos pais por filhos de ambos os sexos) na estimação do efeito de filhos sobre a participação das mães no mercado de trabalho. Como vimos, devido às diferenças metodológicas entre essas estratégias de estimação, os diferenciais entre os efeitos do primeiro, do segundo e do terceiro (ou mais) filhos podem estar refletindo não apenas o impacto de cada ordem de nascimento do filho sobre a participação laboral feminina, mas também o fato de estarmos utilizando variáveis e métodos diferenciados, o que pode afetar a comparabilidade dos resultados.

Com relação à utilização da ocorrência de natimortos e gêmeos, destaca-se ainda o fato de que o efeito de filhos estimado inclui o próprio efeito de experimentar o evento. Isso significa que, no caso em que estimamos o efeito do segundo filho empregando como proxy o nascimento de gêmeos, o efeito encontrado capta também o próprio impacto de ter gêmeos sobre a participação feminina no mercado de trabalho; o que explica o fato de o efeito do segundo filho ter sido superior ao do primeiro sobre a presença feminina na PEA.

Tomando como pano de fundo todas essas questões metodológicas, alguns resultados merecem destaque por sua contribuição para o entendimento de como tem se dado o efeito de filhos sobre a inserção feminina no mercado de trabalho brasileiro, nas últimas décadas, já que, como mencionado por Lérida (2006), são raros os estudos que analisam esse efeito em países em desenvolvimento. No que se refere ao Brasil, de fato, encontramos poucos trabalhos publicados (PAZELLO; FERNANDES, 2004; PAZELLO, 2006; CAMPÊLO; SILVA, 2005), todos recentes e nenhum deles considerou a perspectiva de um efeito diferenciado de filhos segundo sua ordem de nascimento.

Em relação ao efeito do primeiro filho sobre a participação feminina na PEA, tanto na década de 1990 quanto na de 2000 , observamos que tal efeito apresentou tendência de queda entre esses períodos.

Quanto ao efeito do segundo filho, ao considerarmos todas as mães de 15 a 49 anos de idade, inicialmente não verificamos, nos anos 1990, quaisquer efeitos de um segundo filho sobre a probabilidade de estarem inseridas no mercado de trabalho. Na década de 2000, entretanto, um segundo filho passa a afetar negativamente essa probabilidade. Considerando haver a possibilidade de efeitos de curto e longo prazos do nascimento de gêmeos que pareciam estar competindo no sentido de anular o efeito do 
segundo filho sobre a participação feminina no mercado de trabalho, analisamos também esse efeito desagregando a amostra total de mães entre aquelas com filhos de, no máximo, dois anos. De fato, o efeito negativo do segundo filho sobre a participação das mães na PEA passa a existir em ambas as décadas, com magnitude considerável (efeito que deve ser interpretado como um limite-superior do efeito do segundo filho). Assim como encontrado na estimação do efeito do primeiro filho, também quando se trata do segundo filho, nos anos 1990, esse filho afetava mais negativamente a probabilidade de inserção feminina na PEA do que na década posterior.

Diferentemente do que foi observado na estimação do efeito do primeiro e segundo filhos sobre a participação feminina no mercado de trabalho, o efeito do terceiro (ou mais) filho mostrou tendência de aumento entre os anos 1990 e 2000.

Quando comparamos os efeitos de filhos sobre a participação feminina no mercado de trabalho aqui estimados com aqueles reportados em outros estudos, encontramos tendências, direções e magnitudes condizentes não apenas com análises feitas para o Brasil (PAZELLO; FERNANDES, 2004; PAZELLO, 2006), mas também em relação àquelas com dados da Argentina e México (CRUCES; GALIANI, 2003) e dos Estados Unidos (ANGRIST; EVANS, 1998), por exemplo.

Pode-se concluir, enfim, que esse artigo enriquece a discussão acerca da relação entre filhos e inserção feminina no mercado de trabalho, contribuindo também para a formulação de políticas públicas. Isso por-

\section{Referências}

ALIKANI, M. et al. Monozygotic twinning following assisted conception: an analysis of 81 consecutive cases. Human Reproduction, Oxford, v. 18, n. 9, p. 1.937-1.943, Sep. 2003.

ALLEN, V. M. et al. The effect of hypertensive disorders in pregnancy on small for gestational age and stillbirth: a population based study. BMC Pregnancy and Childbirth, v. 4, n. 17, Aug. 2004. que, ao mesmo tempo em que o aumento da participação das mulheres no mercado parece revelar uma mudança cultural positiva na sociedade (em termos de uma maior aceitação dessa nova identidade feminina) que, inclusive, favorece o desenvolvimento econômico, sua associação à queda na fecundidade pode prejudicar o crescimento futuro da força de trabalho e, nesse sentido, ir contra esse desenvolvimento. Além disso, se, por um lado, a presença cada vez maior da mulher no mercado de trabalho pode implicar uma reorganização familiar, já que diminui o tempo disponível das mães com os filhos (o que pode afetar o investimento em capital humano destes - saúde, nutrição, educação, etc.), por outro, esses mesmos filhos podem ser considerados um entrave ao crescimento profissional das mulheres, no que se refere tanto aos diferenciais salariais quanto aos tipos de ocupação (PAZELLO, 2006).

Entretanto, ainda há muito que ser feito nessa área. Seria interessante, por exemplo, observar se mães têm comportamentos diferenciados em relação não apenas à sua participação ou não no mercado de trabalho, mas também à intensidade do seu trabalho (como horas semanais trabalhadas e salários diferenciados). Também nos resta verificar como se dá a influência da paternidade sobre a participação masculina no mercado de trabalho no Brasil (se é que essa influência existe). Outros aspectos que merecem ser analisados são, entre outros, as diferenças regionais, de educação ou raça que porventura existam no estudo da relação filhos/trabalho feminino. Essas são perguntas para a nossa agenda de pesquisa futura.

ANGRIST, J. D.; EVANS, W. N. Children and their parent's labor supply: evidence from exogenous variation in family size. American Economic Review, Nashville, v. 88, n. 3, p. 450-77, Jun. 1998.

BECKER, G. S. A treatise on the family. Cambridge, Massachusetts: Harvard University, 1981. 
BRONARS, S. G.; GROGGER, J. The economic consequences of unwed motherhood: using twin births as a natural experiment. The American Economic Review, Nashville, v. 84, n. 5, p. 1.141-1.156, Dec. 1994

BROSKY, G. Why do pregnant women smoke and can we help them quit? Canadian Medical Association Journal, Ottawa, v. 152, n. 2, p. 163-166, Jan. 1995.

CAMPÊLO, A. K.; SILVA, E. N. Filhos e renda familiar: uma aplicação do efeito quantílico de tratamento. Pesquisa e Planejamento Econômico, Rio de Janeiro, v. 35, n. 3, p. 355-377, dez. 2005.

COLLETTO, G. M. D. D.; SEGRE, C. A. M.; BEIGUELMAN, B. Twinning rate in a sample from a Brazilian hospital with a high standard of reproductive care. Sao Paulo Medical Journal, São Paulo, v. 119, n. 6, p. 216-219, Nov. 2001.

CRUCES, G.; GALIANI, S. Generalizating the causal effect of fertility on female labor supply. Ann Arbor: University of Michigan Business School; Willian Davidson Institute, 2003 (Working paper, 625).

CURRIE, J. When do we really know what we think we know? Determining causality. Washington, DC: NICHD Administration for Children and Families, 2003.

DEHEJIA, R. H.; WAHBA, S. Propensity score matching methods for nonexperimental studies causal studies. The Review of Economics and Statistics, Cambridge, v. 84, n. 1, p. 151-161, Feb. 2002.

ELLER, A. G.; BRANCH, D. W.; BYRNE, J. L. B. Stillbirth at term. Obstetrics \& Gynecology, New York, v. 108, n. 2, p. 442447, Aug. 2006.

JACOBSEN, J. P.; PEARCE III, J. W.; ROSENBLOOM, J. L. The effects of childbearing on married women's labor supply and earnings: using twin births as a natural experiment. Journal of Human Resources, United States, v. 34, n. 3, p. 449-74, Summer 1999.

GOLDIN, C. Career and family: college women look to the past. In: BLAU, F. D.;
EHRENBERG, R. G. (Eds.). Gender and family issues in the workplace. New York: Russell Sage Foundation, 1997.

GOLDIN, C.; KATZ, L. F. The power of the pill: oral contraceptives end women's career and marriage decisions. The Journal of Political Economy, Chicago, v. 110, n. 4, p. 730-770, Aug. 2002.

HOEKSTRA, C. et al. Dizygotic twinning. Human Reproduction Update, Oxford, v. 14, n. 1, p. 37-47, Jan./Feb. 2008.

HÖGBERG, L.; CNATTINGIUS, S. The influence of maternal smoking habits on the risk of subsequent stillbirth: is there a causal relation? BJOG: An International Journal of Obstetrics and Gynaecology, Oxford, v. 114, n. 6, p. 699-704, Feb. 2007.

JANNUZZI, P. M. Modelo alternativo para projeção de forca de trabalho: dos condicionantes econômicos às taxas de atividade. Método e resultados para a Grande São Paulo em 2005. Revista Brasileira de Estudos de População, Rio de Janeiro, v. 17, n. 1/2, p. 141-162, jan./dez. 2000.

KESMODEL, U. et al. Use of alcohol and illicit drugs among pregnant Danish women, 1998. Scandinavian Journal of Public Health, v. 31, n. 1, p. 5-11, Jan. 2003.

LÉRIDA, J. L. de. The impact of exogenous variation in family size on women's labor force participation. In: CONFERENCE OF THE EUROPEAN SOCIETY FOR POPULATION ECONOMICS, 20, 2006, Verona. Anais... Verona: ESPE, 2006.

MACINTOSH, M. C. Perinatal mortality and congenital anomalies in babies of women with type 1 or type 2 diabetes in England, Wales, and Northern Ireland: population based study. British Medical Journal, London, v. 333, n. 177, Jun. 2006.

MARON, L.; MEULDERS, D. Having a child: a penalty or bonus for mother's and father's employment in Europe? Bruxelas: Universit'e Libre de Bruxelles (DULBEA), Fev. 2008 (Working paper series, 08-05.RS).

PAZELLO, E. T. A maternidade afeta o engajamento da mulher no mercado de 
trabalho? Um estudo utilizando o nascimento de gêmeos como um experimento natural. Estudos Econômicos, São Paulo, v. 36, n. 3, p. 507-538, jul./set. 2006.

MOFFITT, R. Remarks on the analysis of casual relationships in population research. Baltimore: Johns Hopkins University, 2003.

PAZELLO, E. T.; FERNANDES, R. A maternidade e a mulher no mercado de trabalho: diferença de comportamento entre mulheres que têm e mulheres que não têm filhos. In: ENCONTRO DA ASSOCIAÇÃO NACIONAL DE PÓS-GRADUAÇÃO EM ECONOMIA, 31. Anais... João Pessoa: Anpec, 2004.

PISON G.; COUVERT, N. The frequency of twin births in France. The triple influence of biology, medicine and family behaviour. Population, Paris, v. 59, n. 6, p. 765-94, Nov./Dez. 2004.

RIOS-NETO, E. L. G. O impacto das crianças sobre a participação feminina na PEA: o caso das mulheres casadas urbanas. In: ENCONTRO DA ASSOCIAÇÃO BRASILEIRA DE ESTUDOS POPULACIONAIS, 10, 1996, Belo Horizonte. Anais... Belo Horizonte: Abep, 1996, v. 1, p. 517-534.

RIOS-NETO, E. L. G.; WAJMANN, S. Participação feminina na população economicamente ativa no Brasil: alternativas para projeções de níveis e padrões. Pesquisa e Planejamento Econômico, Rio de Janeiro, v. 24, n. 2, p. 203-234, maio 1994.

ROSENBAUM, P. R.; RUBIN, D. B. The central role of propensity score in observational studies for causal effects. Biometrika, London, v. 70, n.1, p. 41-55, Apr. 1983.

SCORZAFAVE, L. G. A evolução e os determinantes da participação feminina no mercado de trabalho brasileiro. Dissertação (Mestrado em Economia) - Instituto de Pesquisas Econômicas da Faculdade de Economia, Administração e Contabilidade, USP, São Paulo, 2001.

SEDLACEK, G. L.; SANTOS, E. C. A mulher cônjuge no mercado de trabalho como estratégia de geração de renda familiar. Rio de Janeiro: Ipea, 1991 (TD 209).

SMITH, H. L. Matching with multiple controls to estimate treatment effects in observational studies. Sociological Methodology, Oxford, v. 27, p. 325-53. 1997.

SOARES, Y. Viés de gênero em consumo. Pesquisa e Planejamento Econômico, Rio de Janeiro, v. 32, n. 2, ago. 2002.

SOUTO-MAIOR, H. P. Mulher, família e trabaIho no Nordeste (1970-1987): o que dizem os dados publicados dos censos demográficos e PNADs. In: ENCONTRO DA ASSOCIAÇÃO BRASILEIRA DE ESTUDOS POPULACIONAIS, 7, 1990, Caxambu. Anais... Caxambu: Abep, 1990, v. 1, p. 175-208.

WINSHIP, C.; RADBILL, L. Sampling weights and regression analysis. Sociological Methods and Research, v. 23, n. 2, p. 230257, 1994.

WISBORG, K. Maternal consumption of coffee during pregnancy and stillbirth and infant death in first year of life: prospective study. British Medical Journal, London, v. 326, n. 420, Feb. 2003.

\section{Resumen}

La relación entre paridez y trabajo femenino en Brasil

El objetivo de este artículo es analizar el efecto de los hijos sobre la participación de las mujeres en la Población Económicamente Activa (PEA), observando la evolución temporal de este efecto desde los años 90 . Asimismo, en base al hecho de que cada hijo pueda presentar un efecto diferenciado sobre la decisión de trabajar de las madres, se estimó, por separado, el efecto del primer, del segundo y del tercer (o más) hijos sobre la participación femenina en la PEA. De manera general, los resultados sugieren que, independientemente del orden de nacimiento, 
los hijos disminuyen la probabilidad de participación de las mujeres en el mercado de trabajo. Además, entre las décadas de 1990 y 2000 , el efecto negativo del primer y segundo hijos sobre la participación femenina en el mercado de trabajo perdió magnitud, al mismo tiempo que el efecto del tercer hijo ganó importancia.

Palabras-clave: Fecundidad. Oferta de trabajo. Mujeres. Brasil.

\section{Abstract}

The relationship between childbirth and women's labor in Brazil

The objective here is to analyze the effect of having children on women's share in the economically active population, observing the temporal evolution of this effect during the 1990s. In addition, based on the fact that each child may exert a different effect on a mother's decision to work or not, the effect of the first, the second and the third (or more) children on this woman's share in the economically active population were estimated. In general the findings suggest that, regardless of order of birth, children reduce the likelihood of women to participate in the labor market. Also, during the 1990s and the decade of 2000 the negative effect of the first and second children on women's share in the labor market fell in impact, whereas the effect of a third child took on some importance.

Keywords: Fecundity. Job supply. Women. Brazil.

Recebido para publicação em 03/11/2010 Aceito para publicação em 08/03/2011 